\title{
Considerações sobre o ontem e o hoje da Saúde Mental brasileira
}

\author{
AMARANTE, Paulo. \\ Saúde mental e atenção psicossocial. \\ $4^{\mathrm{a}}$. edição, $2^{\mathrm{a}}$. reimpressão \\ Rio de Janeiro: Editora Fiocruz, 2017. \\ | 1 Júlia Romualdo Bezerra da Silva | \\ 1 Psicologia, Universidade Estácio de Sá. Rio de Janeiro-RJ, Brasil (juliromualdo@gmail.com). ORCID: 0000-0003-2722-9457 \\ Recebido em: 17/05/2018 \\ Aprovado em: 18/11/2018 \\ Revisado em: 24/05/2019
}

DOI: http://dx.doi.org/10.1590/S0103-73312019290218

O campo da Saúde Mental no Brasil está marcado pelas açóes incoerentes ocorridas nas décadas passadas, durante o reinado do modelo hospitalocêntrico, que por anos utilizou de métodos violentos e invasivos nos pacientes. Contudo, por volta do fim da década de 1970, surgiram muitos debates acerca da loucura e o que de fato seria o sujeito louco; discussóes que invadiram as instituiçóes psiquiátricas brasileiras dando aos poucos um novo olhar sobre o louco. Eventos sobre as relaçóes de tratamento no modelo asilar eram cada vez mais frequentes, e o que eram os direitos humanos e até onde a violência no tratamento tornava o método do isolamento ineficaz era o tema principal nos encontros de debates em saúde.

Esses debates sobre a saúde mental foram ganhando força não apenas no meio da saúde em geral, mas, no dia a dia da sociedade, que por sua vez, se indignava cada vez mais com o trato violento imposto pelo modelo falido da internação. Em 1989, o deputado brasileiro Paulo Delgado levou ao Congresso Nacional uma nova proposta de tratamento psiquiátrico para os usuários de serviço da saúde mental brasileira. Em 2001, um projeto derivado dessa proposta originou a Lei Federal $n^{\circ} 10.216$, que veio abarcar os direitos dos portadores de transtornos mentais, uma conquista na legislação brasileira, uma vez que tal lei reorientou todo o tratamento psiquiátrico e o atendimento em saúde, sobretudo nos dispositivos de atenção comunitária básica. 
Paulo Amarante, autor do livro em questão, Saúde mental e atenção psicossocial, é considerado um dos pioneiros do movimento reformista da psiquiatria. Nascido em Colatina, Espírito Santo, formou-se em 1976 em medicina pela Escola de Medicina Santa Casa de Misericórdia, especializou-se em psiquiatria no Rio de Janeiro, onde vem desenvolvendo desde então diversas pesquisas e publicaçôes na área da Saúde Mental. Ocupou diversos cargos de importância, como o de presidente nacional do Centro Brasileiro de Estudos de Saúde (CEBES) e representante eleito do Movimento Nacional da Luta Antimanicomial na Comissão Intersetorial de Saúde Mental do Conselho de Saúde. Possui ainda mestrado em Medicina Social e doutorado em Saúde Pública, além do título de Doutor honoris causa pela Universidade Popular das Madres da Plaza de Mayo. Atualmente é editor da Revista Saúde em Debate e pesquisador titular da Fiocruz.

O presente livro, lançado em 2007, sendo sua $4^{a}$ edição, publicada em 2017 pela Editora Fiocruz, faz parte de uma coleçáo nomeada Temas em Saúde, cujo objetivo é trazer aos leitores uma reflexão sobre os panoramas de diversas áreas da saúde (AMARANTE, 2017). Trata-se de uma leitura que possui escrita instigadora e reflexiva sobre o percurso da assistência psiquiátrica, traçando uma linha do tempo desde os primórdios da psiquiatria e suas fundamentaçóes teóricas que originaram o modelo asilar, até os pensamentos questionadores de Foucault, adentrando um pensamento antimanicomial e fundamentador do que hoje conhecemos da saúde mental (FOUCAULT, 2004).

Partindo para os capítulos, temos o primeiro, intitulado "Saúde mental, territórios e fronteiras", onde Amarante parte da inferência abstrata e extensiva que a denominada área da saúde mental se faz reconhecer, fazendo o leitor refletir sobre o que de fato é uma saúde mental no conceito mais autêntico do termo. Para o autor, a saúde mental não está restrita apenas na vertente da psiquiatria, a qual lida com a fisiologia e semiologia dos transtornos mentais, mas é um conceito para além disso, estando incluso nas diversas áreas de saúde e sociedade em que o sujeito está inserido. Portanto, toda área de estudo que lide com o sujeito em si é parte representante da saúde mental.

Amarante traz, ainda no primeiro capítulo, questionamentos sobre a diferença entre os termos "doença mental" e "saúde mental", e provoca reflexóes sobre se uma expressão seria o oposto da outra e quais são os limites do campo de atuação na saúde mental. É um campo que abrange contribuições simultâneas, atravessando 
diversas áreas de saberes e fazendo do sujeito e do coletivo social objetos de estudo complexos e com as mais variáveis condiçôes de observação.

No capítulo seguinte, "Uma instituição para loucos, doentes e sãos”, o autor inicia o diálogo com o leitor sobre as condiçôes anteriores do tratamento psiquiátrico. Nesse momento, o autor introduz as contribuiçôes de Philippe Pinel, conhecido como "o pai da psiquiatria", e a importância que este teve nos processos de revolução da saúde mental na França, exemplificando a abrangência dessa área na economia, política e meio social em geral.

Ainda no segundo capítulo, Amarante faz a distinção sobre como ocorreu o processo de evolução institucional do hospital: o que antes era visto como lugar de refúgio para os pobres adoentados passa a ser uma instituição médica por excelência, um ambiente de cuidado terapêutico por si só. Face a esta nova posição do hospital, é que se inicia o processo de isolamento pineliano, mas que ao passar do tempo, tornou-se motivo de adoecimento maior, incluindo a própria instituição de cuidado.

No terceiro capítulo, "Das psiquiatrias reformadas às rupturas com a psiquiatria", o autor dá voz a fortes críticas da prática alienista, assim como o próprio modelo de ciência positivista que deu a legitimidade da prática do isolamento terapêutico. A princípio, este modelo seria uma tentativa de tratamento para a recuperação da sanidade dos loucos, visto que os tratamentos obedeciam a princípios e medidas que buscavam uma reeducação da mente como tentativa de diminuir as alucinações e delírios que retiravam o crédito social desses sujeitos.

Amarante traz as colonias de alienados como um método de tratamento, utilizando a obra do autor brasileiro Machado de Assis, O Alienista, como exemplo do antigo regime. Entretanto, com o passar do tempo, esses ambientes acabaram por tornar-se equivalentes aos antigos hospitais psiquiátricos, superlotados e desumanos, atendendo somente aos interesses daqueles que tinham maior poder aquisitivo e queriam se livrar dos sujeitos a beira da sociedade.

Diante deste cenário, vários países iniciaram movimentações que compartilhavam de um novo ideal sobre a loucura, reivindicando direitos que acreditavam estar esquecidos para os doentes mentais. Amarante tem o cuidado de separar os iniciantes da reforma psiquiátrica em dois grupos, explicando a diferença ideológica entre eles. O primeiro grupo seria formado pelos defensores da Comunidade Terapêutica e pela Psicoterapia Institucional; e o segundo, pelos da Anipsiquiatria e Psiquiatria 
Democrática. O autor destaca importância desses grupos, mesmo não estando no sentido literal da reforma.

Partindo dessas premissas teóricas, a leitura percorre os fundamentos que caracterizam os grupos até o momento de eclosão da atenção psicossocial, adentrando os pensamentos de Maxwell Jones e suas colaboraçóes para o campo da Saúde Mental. O autor também cita François Tosquelles como contribuinte-chave para a comunidade terapêutica, com a proposta de resgate do trabalho terapêutico e a ressignificaçáo do coletivo. É possível compreender a origem do conceito de regionalização na saúde, em especial a saúde mental, que mais tarde seria eleito como um dos princípios do Sistema Único de Saúde (SUS). Ainda é destacada a importância da equipe multiprofissional no amparo da saúde. Assim, o capítulo se encera com a contribuição de Gerald Caplan no viés preventivo da psiquiatria e a divisão dos três níveis de prevenção.

No quarto capítulo, "Estratégias e dimensões do campo da Saúde Mental e atenção psicossocial”, são retomadas as características do modelo psiquiátrico, especificando a hospitalização como pressuposto da doença mental. O autor deixa clara sua opinião quanto à aproximação do sistema psiquiátrico de saúde e as instituiçôes carcerárias e penitenciárias. Uma vez que a fundamentação desse sistema está na observação e controle disciplinante, torna-se desafiador qualquer processo que vise além dos processos já conhecidos.

O autor explica, com um texto claro, que o processo da reforma psiquiátrica está intimamente associado aos avanços da ciência. Destaca-se aqui a importância de se atentar para a mudança de olhar dos serviços, que passam a lidar com pessoas, e não mais focar nas doenças. Graças a essa mudança, houve uma ruptura da teoria que caminhou para o processo de atenção psicossocial vigente até hoje na saúde mental, construindo um novo olhar para os loucos e a própria loucura. Após essas exposiçóes, Amarante caminha para a questáo dos direitos humanos, e explica a importância da Lei $\mathrm{n}^{\circ} 10.216 / 2001$ e as demais leis subsequentes da reforma psiquiátrica, que amparam o sujeito em sofrimento mental.

Finalmente, o quinto e último capítulo, "Caminhos e tendências das políticas de saúde mental e atenção psicossocial no Brasil", expóe a importância da referência ao termo "usuário", para aqueles sujeitos que desfrutam do direito a saúde pela legislação do SUS. O conjunto de princípios que abarcam o campo da Saúde Mental e atenção psicossocial brasileira é destacado pelas estratégias de residencialidade 
e emancipação dos sujeitos, o apoio das cooperativas, centros de convivência e empresas sociais, juntamente com a atenção primária em saúde, que ao contrário de antigamente, enfoca a saúde familiar objetivando reverter o olhar exclusivo na doença e reforçando o sujeito como todo.

Ao final do livro, Amarante deixa sugestôes de outras leituras e filmes que abordam o tema da saúde mental e atenção psicossocial no cenário contemporâneo. Apesar de toda evoluçáo do sistema de saúde e da psiquiatria em geral, o hospital psiquiátrico ainda é uma instituição que existe, e as muitas formas de permanência desse sistema excludente aniquilam os pressupostos reformistas da cidadania, autonomia e liberdade para aquele considerado louco.

É importante destacar que a leitura desse livro é um grande ganho para os interessados em saúde mental. $\mathrm{O}$ autor preocupou-se em organizar a escrita de forma que construísse uma linha do tempo até a atual situação da psiquiatria e atenção psicossocial, explicando de forma breve, porém não resumida, os principais impactos da reforma psiquiátrica no Brasil.

O livro traz de forma fácil a reflexão sobre como o sujeito louco ainda é visto socialmente e as barreiras que a atual conjuntura do SUS tem que romper para uma igualdade real dos direitos humanos, não apenas legais, mas sobretudo eticamente permanente. Recomenda-se essa leitura a todos os estudantes e profissionais que possuam contato com a área da saúde, além dos demais curiosos sobre o assunto, pois é uma oportunidade enriquecedora de reflexão e chamamento de responsabilidade social.

\section{Referências}

AMARANTE, P. Saúde mental e atenção psicossocial. 4. Ed. Rio de Janeiro: Editora Fiocruz, 2017. FOUCAUlT, M. A história da loucura. 7. ed. São Paulo: Perspectiva, 2004.

BRASIL. Ministério da Saúde. Lei n. ${ }^{\circ}$ 10.708, de 31 de julho de 2003. Institui o auxílio reabilitação para pacientes egressos de internaçôes psiquiátricas 103 (Programa De Volta Para Casa). Diário Oficial da União, p. 3, Seção 1, 2003. 